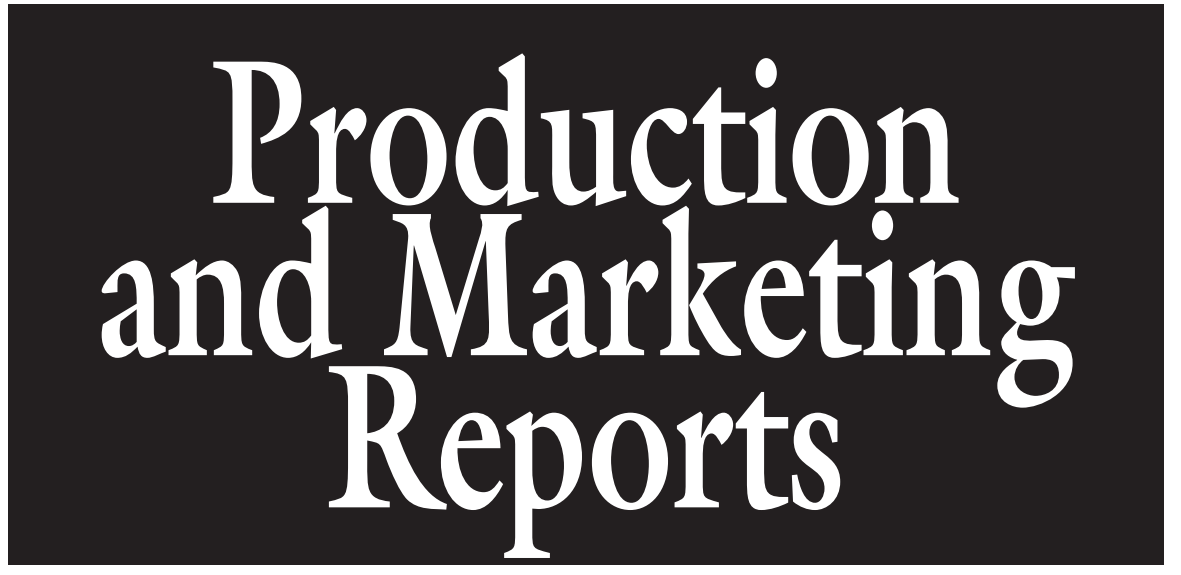

\section{Consumer Preferences and Willingness to Pay for Existing and New Apple Varieties: Evidence from Apple Tasting Choice Experiments}

\author{
Chengyan Yue ${ }^{1,3,5}$ and Cindy Tong ${ }^{2,4}$
}

ADDITIONAL INDEX WORDs. marketing, apple varieties, quality evaluation

SUMmARY. We used choice experiments to investigate consumers' preferences and willingness to pay (WTP) for various apple (Malus $\times$ domestica) varieties. The experiments also asked consumers to evaluate a series of quality attributes by allowing them to taste apples. The choice experiments were conducted in real markets where consumers were making fruit purchases to eliminate any decontextualized biases. The objectives of this study were to determine how much consumers are willing to pay for 13 new and existing apple varieties and learn what quality attributes consumers' like or dislike in new vs. older apple varieties. Results show that compared with other apple varieties, participants were willing to pay the highest prices for 'SweeTango ${ }^{\circledR}$ ', followed by 'Zestar! ${ }^{\text {TM}}$ ' and 'Honeycrisp'. Frequent and infrequent buyers were willing to pay significantly different amounts for most of the studied varieties. In addition to WTP estimates, our study also shows what quality attributes consumers consider as improvements compared with existing varieties. Combined with objective measures of these quality attributes, our transdisciplinary study will help apple breeders make more targeted breeding decisions by better understanding what quality attributes consumers like or dislike about the studied varieties.

$\mathrm{T}$ The U.S. apple industry is experiencing increasingly intensive competition (Axelson and Axelson, 2000). This intense competition coupled with consumers'

We thank Andrea Appel, Ross Peterson, Kelsey Propsom, Alicia Rihn, Benjamin Tietge, and Diana Trujillo for helping with taste tests, Tim Byrne and James Luby for suggesting culivars, and David Bedford and Pine Tree Apple Orchard for supplying apples. We thank Xiaofang Guo for helping with the data analysis.

${ }^{1}$ Departments of Horticultural Science and Applied Economics and Bachman Endowed Chair in Horticultural Marketing, University of Minnesota-Twin Cities, St. Paul, MN 55108

${ }^{2}$ Department of Horticultural Science, University of Minnesota-Twin Cities, St. Paul, MN 55108

${ }^{3}$ Assistant Professor

${ }^{4}$ Associate Professor

${ }^{5}$ Corresponding author. E-mail: yuechy@umn.edu. increasing expectations for high food quality (McCluskey et al., 2007) has driven the apple industry to continuously improve the quality of existing apple varieties and develop new ones. In the recent past, many new varieties have been released but not all of them have succeeded in the marketplace (The Packer, 2010).

The success of an apple variety depends on its quality attributes. Quality attributes can be divided into three categories: search characteristics, experience characteristics, and credence characteristics. Search characteristics are those attributes that can be ascertained before the purchase; as for example, the color and size of apples. In contrast, experience characteristics can only be established by experiencing the product, such as the crispness, juiciness, sweetness, and tartness of apples. Credence characteristics cannot be validated (or can be validated only at very high cost) by consumers either before or even after the purchase. An example of a credence characteristic is the health benefit derived from consuming apples. Search characteristics of apples, such as size and color, are certainly important since these appearance factors do influence consumer apple choice. Experience characteristics such as sweetness, tartness, crispness, juiciness, etc., are even more important since these experience characteristics determine if consumers like apples they have purchased and come back and make repeat purchases, which ultimately determines the demand for the apple variety (McCluskey et al., 2007).

There is some literature on consumer WTP for apples but mostly focused on some particular search or credence characteristics, such as ecolabeled (Loureiro et al., 2002), food safety attributes (Rozan et al., 2004), organic attributes (Yue et al., 2009), local, organic, and genetically modified organism-free attributes (Loureiro and Hine, 2002), and cosmetic damage (Yue et al., 2007). Many of these studies were particularly interested in specific characteristics and one apple variety rather than using multiple varieties to test consumers' preferences and WTP for the characteristics. Some studies have investigated consumer preferences for apple search or experience characteristics. These studies have been driven by two forces: improving the competitiveness of apples in response to needs of the industry and increasing consumption of fruits to improve public health (Harker et al., 2003).

According to Harker et al. (2003), assessing the impact of quality attributes on consumer preferences and choice of fruits is difficult. This is because experience characteristics, such as crispness,

\begin{tabular}{llll}
\hline $\begin{array}{l}\text { Units } \\
\begin{array}{l}\text { To convert U.S. to SI, } \\
\text { multiply by }\end{array}\end{array}$ & U.S. unit & SI unit & $\begin{array}{l}\text { To convert SI to U.S., } \\
\text { multiply by }\end{array}$ \\
\hline 0.4536 & $\mathrm{lb}$ & $\mathrm{kg}$ & 2.2046
\end{tabular}


juiciness, and tartness, require consumers to eat the products, which is not always easy due to experimental resource constraints. Many studies that allow consumers to taste apples are often conducted in formal tasting facilities, lacking in usual contextual and situational associations with real fruit purchases (Harker et al., 2003).

Our study successfully overcomes the aforementioned difficulties. We used choice experiments to investigate consumers' preferences and WTP for various apple varieties and then evaluated a series of quality attributes by allowing them to taste apples. The choice experiments were conducted in real markets where consumers were making fruit purchases, which can eliminate any decontextualized biases. The use of a choice format has gained popularity among consumer preference and WTP researchers. Lusk and Schroeder (2004) developed the choice format with posted prices in different scenarios to investigate consumers' WTP for food quality attributes. Alfnes et al. (2006) used a choice experiment to investigate consumers' WTP for salmon with different colors.

Taste and texture account for most of the variability in consumer liking of apple fruit (Harker et al., 2003). Consumers' targets for texture and taste differ between individuals, which suggest that each apple variety needs to be considered in relation to its specific niche market. Because consumer preferences are dependent on previous experiences and expectations, the release of new varieties may change consumer expectations and therefore their preferences. In the past couple of decades, several new apple varieties have been developed and released by the apple breeding program at the University of Minnesota. The 'Honeycrisp' apple was released in 1991 and has rapidly become a prized commercial product in the United States and worldwide. The 'Zestar!' ${ }^{\mathrm{TM}}$ ' apple, released in 1998, was bred to survive in cold climates and to be sold as an early season apple. 'SweeTango ${ }^{\circledR}$ ' is the brand name for the premium quality apple fruit produced from the variety 'Minneiska', which was released in 2009 and is a cross between 'Honeycrisp' and 'Zestar! ' Since 'SweeTango $\AA$ ' has only been available in the marketplace since the fall of 2010, consumer preferences and WTP for it in comparison with other apple varieties are still not known. To our knowledge, there is no comprehensive study that has systematically compared consumer preferences for the varieties 'Honeycrisp', 'Zestar! ${ }^{\mathrm{TM}}$, and 'SweeTango $\circledR$ ' with other new and existing varieties.

An objective of this study was to determine if consumers are willing to pay more for 'SweeTango ${ }^{\circledR}$ ', 'Honeycrisp', and 'Zestar! ${ }^{\mathrm{TM}}$, in comparison with other apple varieties. If so, by how much? What quality attributes do consumers like or dislike in new vs. older apple varieties? Are there any differences between frequent apple buyers and infrequent apple buyers in terms of their WTP for various apple varieties? The results of this research can be useful for apple growers, wholesalers, and shippers in making their production and marketing decisions.

\section{Materials and methods}

Choice experiment. The two attributes in the choice experiments were apple varieties and prices. The varieties included in our study were 'Connell Red', 'Cortland', 'Fuji', 'Gala', 'Ginger Gold', 'Haralson', 'Honeycrisp' (organic and conventional), 'Jazz ${ }^{\mathrm{TM}}$, 'SnowSweet ${ }^{\circledR}$ ', 'Sweet Sixteen', 'SweeTango®', and 'Zestar! 'MM, Of these, 'Connell Red', 'Cortland', 'Ginger Gold', 'Haralson', conventionally grown 'Honeycrisp', 'SnowSweet®', 'Sweet Sixteen', and Zestar! ${ }^{\text {TM, }}$ were harvested from the Horticultural Research Center orchards in Chanhassen, $\mathrm{MN}$, at commercial maturity. 'SweeTango®' was provided by a commercial orchard. The other varieties were purchased from local supermarkets at the time of the studies. The price levels per pound included in our study were $\$ 1.49, \$ 1.69, \$ 1.99$, $\$ 2.49, \$ 2.99$, and $\$ 3.69$ and were based on actual price levels in different stores in Minnesota.

Because we were interested in consumer preference and WTP for various apple varieties based merely on appearance and taste instead of brand name, the variety names were not given to participants. This was important because we were testing new varieties that may have been unfamiliar to consumers against established varieties with brand identity, and brand name may have a significant effect on consumer preferences. Instead, each variety was represented by a computer-generated random three- digit number. To avoid ordering effects on consumer evaluation, the sequences of apples presented to participants were randomly allocated.

Participants were given one piece of apple for each variety they were asked to evaluate. In addition to the pieces of apples provided to participants, three whole apples of each variety were displayed on a large table so that participants had the chance to evaluate both the appearance and taste of apples. Participants tasted the apples and then were presented with a series of pricing scenarios and asked to choose one alternative in each pricing scenario. If none of the alternatives was of interest, participants could choose "none of these." To lessen the cognitive burden on participants, only two alternatives were usually included in each scenario in a choice experiment.

In our experiments, each scenario had two alternatives described by apple varieties and price levels. Since it was not practical to ask each participant to choose from all possible scenarios, a fractional factorial design was developed to minimize scenario number and maximize profile variation. The design was developed based on four principles: level balance (levels of an attribute occurred with equal frequency), orthogonality (the occurrences of any two levels of different attributes were uncorrelated), minimal overlap (cases where attribute levels did not vary within a scenario were minimized), and utility balance (the probabilities of choosing alternatives within a scenario were as similar as possible) (Louviere et al., 2000). The fractional factorial design gave each participant sets of eight scenarios to evaluate. The clearly dominant alternatives were eliminated. For a further discussion of factorial design, see Louviere et al. (2000).

To avoid participant tasting fatigue, each person only evaluated six or seven varieties. The varieties were chosen according to the experimental design and variety availability at the time of the experiment. One example of the scenarios is shown in Fig. 1 .

QUALITY ATTRIBUTE EVALUATION. In addition to the choice experiment, in 2010 , participants were also asked to indicate if they liked the following attributes of the corresponding varieties: crispness, tartness, color, aroma, juiciness, sweetness, and firmness. If a participant liked an attribute, for example, crispness, of the variety evaluated, the 
participant would choose "yes," otherwise, "no." One example of the evaluation form is shown in Fig. 2.

SAMPLING. Tables were set up at a farmers' market and a supermarket in the Minneapolis-St. Paul area to conduct the choice experiment in Oct. 2009 and Oct. 2010. Shoppers in the fruit and vegetable sections at the farmers' market and the supermarket were randomly selected to participate in the experiments. To ensure that the sample was representative, only one family member per household was allowed to participate in the experiments. In total, 322 participants completed most of the questions of the survey. Some of the data were not included in the analysis because of one or more missing values; thus, observations of 266 participants were included in the analysis.

Statistical MOdels. Consumers' satisfaction derived from choice and consumption of different apples relied on measurable factors, including consumers' characteristics and their preferences for the apple varieties and price levels. Consumer characteristics included were age, gender, education level, income, and household size. Because the dependent variable was categorical (whether the alternative was chosen by participants), we used a mixed logit model to estimate the probability values of a consumer's choice of certain apple varieties. Different from the standard logit model, the mixed logit model allows correlation in factors. We used the mixed logit model to capture all possible correlations for responses from the same participant and scenario. The statistical model was

$$
U_{n i s}=\beta^{\prime} x_{n i s}+\eta^{\prime}+\varepsilon_{n i s},
$$

where $U_{\text {nis }}$ was the utility of individual $n$ from alternative $i$ in scenario $s$; $x_{n i s}$ was vectors of observed variables relating to alternative $i$ and individual $n ; \beta$ was a vector of fixed coefficients; $\eta$ was a vector of normally distributed random terms with mean of zero and standard deviation $\sigma_{\eta}$, which was used to capture the possible correlations (which is also called individual effects); and $\varepsilon_{n i s}$ was an identical and independent extreme value error term. The standard logit model is a special case of the mixed logit model, where $\eta$ has zero variance. The density of $\eta$ was denoted by $f(\eta \mid \Omega)$, where $\Omega$ was the fixed parameter vector of the distribution. For a given $\eta$, the conditional choice probability of alternative $i$ was a standard logit

$$
L_{i}(\eta)=\frac{e^{\beta^{\prime} x_{i}+\eta^{\prime}}}{\sum_{j \in J} e^{\beta^{\prime} x_{j}+\eta^{\prime}}}
$$

Consequently, the unconditional choice probability $P$, in the mixed logit model was the logit formula integrated overall values of $\eta$ with density of $\eta$ as weights

$$
P_{i}=\int L_{i}(\eta) f(\eta \mid \Omega) d \eta
$$

Analysis of variance (ANOVA) analysis was used to test the differences between frequent buyers' and infrequent buyers' demographic background information. ANOVA provides a statistical test of whether the means of several groups are all equal.

Consumer evaluation of differences in the quality attributes of various

\begin{tabular}{|l|l|ll|l|}
\hline Scenario 1 & $\square$ Variety $885 \$ 2.49$ & $\square$ Variety 828 & $\$ 1.99$ & $\square$ none of these \\
\hline
\end{tabular}

Fig. 1. An example of the scenarios participants evaluated in apple tasting choice

\begin{tabular}{|c|c|c|c|c|c|c|}
\hline \multicolumn{7}{|c|}{ Do you like the following attributes of the corresponding variety? } \\
\hline Crispness & Tartness & Color & Aroma & Juiciness & Sweetness & Firmness \\
\hline Yes & Yes No & Yes No & $\begin{array}{l}\text { Yes No } \\
\end{array}$ & $\begin{array}{l}\text { Yes } \\
\end{array}$ & $\begin{array}{l}\text { Yes } \\
\end{array}$ & $\begin{array}{ll}\text { Yes } & \text { No }\end{array}$ \\
\hline
\end{tabular}
experiments at a farmers' market and a supermarket in the Minneapolis-St. Paul, $\mathrm{MN}$, area in 2009 and $2010 ; \$ 1.00 \mathrm{lb}=\$ 2.2046 / \mathrm{kg}$.

Fig. 2. An example of the quality attributes participants evaluated in apple tasting choice experiments at a farmers' market and a supermarket in the Minneapolis-St. Paul, MN, area in 2010. Participants were asked to rank and evaluate a total of eight different apple varieties.

apple varieties was estimated using the Bonferroni $t$ test. The Bonferroni $t$ test allows many simultaneous comparison statements to be made, while still assuring an overall confidence coefficient is maintained.

To test the hypothesis that frequent and infrequent buyers were similar in their apple choices and WTP, the Hausman test was conducted for the two sets of mixed logit model coefficients for frequent and infrequent apple buyers. The Hausman test is a statistical test that evaluates the significance of an estimator rule used to calculate an estimate of a given quantity based on observed data vs. an alternative estimator and if a statistical model corresponds to the data. The Hausman test statistic follows a chi-square distribution with $\mathrm{df}$ of number of coefficients estimated.

If the hypothesis was not rejected, we used one mixed logit model including both frequent and infrequent apple buyers to do the estimation. Otherwise, we used two mixed logit models to estimate frequent and infrequent buyers' choices of apple varieties separately and conducted $t$ tests for the differences between the frequent and infrequent apple buyers' WTP for each individual apple variety. The maximum likelihood estimation method that was used to estimate coefficients of the mixed logit model, ANOVA, and Bonferroni $t$ test were estimated with Stata 10.0 software (StataCorp, College Station, TX).

\section{Results}

Demographic background of THE SAMPLE. Table 1 summarizes the demographic background information of the sample. On average, participants were aged around 40 years. Seventy-one percent of participants were female, which is consistent with the fact that most grocery shoppers are female (Yue and Tong, 2009). On average, household size ranged from two to three people. The average participant had a college diploma. The average annual income level was between $\$ 50,000$ and $\$ 70,000$. These demographics were similar to that of nationwide apple consumers surveyed in 2009 by The Packer (2010). Regarding past purchases, participants, on average, purchased apples one to three times per month. Ninety-three out of 266 participants purchased apples two to three times per month or more (these participants are referred to as 
"frequent buyers"), and 173 out of 266 participants purchased apples once per month or less (referred to as "infrequent buyers").

We tested if there was a significant difference in the demographic variables between frequent and infrequent buyers. The results are shown in Table 2 and the probability values of an ANOVA test are shown in the last column of the table. From the test results, we can see that frequent buyers were significantly younger than infrequent buyers at the $10 \%$ significance level. Frequent buyers had significantly larger households than infrequent buyers at the $1 \%$ significance level. Frequent buyers had a significantly higher income level than infrequent buyers at the $10 \%$ significance level. There were no significant differences in preference, WTP, and quality evaluation between supermarket and farmers' market participants (results not shown but available upon request).

APPLE VARIETY PREFERENCES. Because significant differences in demographic background variables between frequent and infrequent buyers were found, we ran two separate mixed logit models on the apple choice data for the two groups of participants. As the probability value of the Hausman test was 0.06 , the null hypothesis that the coefficients of the two models were the same was rejected. Since our hypothesis that frequent and infrequent buyers were similar in their choices of apple varieties was rejected, we chose to keep separate the two mixed logit models to estimate consumers' choices of apple varieties for frequent (Model 1 ) or infrequent buyers (Model 2). The estimation results are shown in Table 3 .

To avoid perfect collinearity, we dropped 'SweeTango ${ }^{\circledR}$ ' as a variable and used it as the basis for estimation (the coefficient was set to zero). The demographic variables were included in the estimation but none of them were significant. The individual effects were not significant so a mixed logit model and a standard logit model would generate the same results. From Table 3 we can see that participants preferred 'SweeTango ${ }^{\circledR}$ ' over other varieties because the coefficient of 'SweeTango ${ }^{\circledR}$ ' was zero, whereas the coefficients for all other apple varieties were negative and most of them were significant. This was true for both frequent and infrequent buyers. Frequent

Table 1. Summary statistics of apple tasting choice experiment participants at a farmers' market and a supermarket in the Minneapolis-St. Paul, MN area in 2009 and $2010(N=266)$.

\begin{tabular}{|c|c|c|c|}
\hline Variable & Description & Mean & SD \\
\hline Age & $\begin{array}{l}\text { Participant's age in years } 1=\text { under } 20 \\
\begin{array}{l}2=20-29,3=30-39,4=40-49 \\
5=50-59,6=60 \text { or over }\end{array}\end{array}$ & 3.73 & 1.46 \\
\hline Gender & Gender of participant, $1=$ male, $0=$ female & 0.29 & 0.46 \\
\hline Household & Number of people in the household & 2.47 & 1.21 \\
\hline Education & $\begin{array}{l}\text { The highest level of education } \\
1=\text { Some high school or less } \\
2=\text { High school diploma } \\
3=\text { Some college } \\
4=\text { College diploma } \\
5=\text { Some graduate school } \\
6=\text { Graduate degree }\end{array}$ & 4.29 & 1.28 \\
\hline Income & 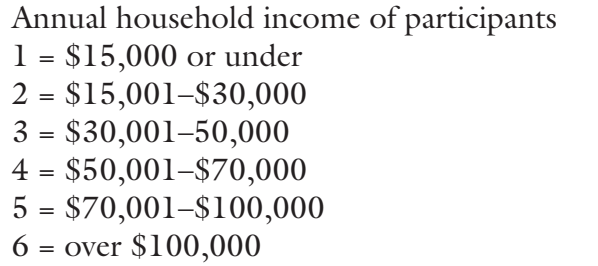 & 4.09 & 1.58 \\
\hline
\end{tabular}

Table 2. Comparison of demographic information between frequent and infrequent apple buyers participating in apple tasting choice experiments at a farmers' market and a supermarket in the Minneapolis-St. Paul, MN area in 2009 and $2010(N=266)$.

\begin{tabular}{|c|c|c|c|c|c|}
\hline \multirow[b]{2}{*}{ Variable } & \multicolumn{2}{|c|}{ Frequent buyer ${ }^{\mathrm{z}}$} & \multicolumn{2}{|c|}{ Infrequent buyer ${ }^{y}$} & \multirow[b]{2}{*}{$P^{\mathrm{x}}$} \\
\hline & Mean & SD & Mean & SD & \\
\hline $\operatorname{Agew}^{w}$ & 3.52 & 1.47 & 3.84 & 1.45 & 0.08 \\
\hline Gender & 0.31 & 0.47 & 0.28 & 0.45 & 0.63 \\
\hline Household & 2.81 & 1.28 & 2.28 & 1.13 & 0.00 \\
\hline Education & 4.28 & 1.39 & 4.30 & 1.22 & 0.90 \\
\hline Income & 4.33 & 1.54 & 3.97 & 1.58 & 0.07 \\
\hline
\end{tabular}

${ }^{2}$ Frequent apple buyers were those participants who purchased apples two to three times per month or more $(n=93)$.

'Infrequent buyers were those participants who purchased apples once per mo. or less $(n=173)$.

${ }^{x}$ Analysis of variance (ANOVA) tests were conducted to see if frequent apple buyers and infrequent apple buyers differed significantly in terms of their age, gender, household size, education level, and income level. If the ANOVA probability value of for a variable was $10 \%$ or less, then the two groups differed significantly in terms of the variable at a $90 \%$ or higher significance level.

whe same scales used in Table 1 were used in calculating the means and standard deviations of the variables.

buyers had the same level of preference for organic 'Honeycrisp' as for 'SweeTango ${ }^{\circledR}$ ' apples because the parameter estimate for organic 'Honeycrisp' was not significantly different from zero and hence had the same level as the base.

Following 'SweeTango ${ }^{\circledR}$ ' and organic 'Honeycrisp', frequent buyers' preferences for apple varieties occurred in the following sequence from most to least preferred: 'Zestar! ' tional 'Honeycrisp', 'SnowSweet $\AA$ ', 'Connell Red', 'Gala', 'Keepsake', 'Ginger Gold', 'Haralson', 'Cortland', 'Jazz ${ }^{\text {TM, }}$ 'Sweet Sixteen', and 'Fuji'.
Following 'SweeTango ${ }^{\circledR}$ ', infrequent buyers' preferences for apple varieties were as follows from most to least preferred: organic 'Honeycrisp', 'Zestar! ${ }^{\mathrm{TM}}$, conventional 'Honeycrisp', 'SnowSweet ${ }^{\circledR}$ ', 'Jazz ${ }^{\mathrm{TM}}$, 'Ginger Gold', 'Connell Red', 'Fuji', 'Keepsake', 'Haralson', 'Gala', 'Cortland', and 'Sweet Sixteen'. The top five most preferred apple varieties were the same for frequent and infrequent buyers: 'SweeTango ${ }^{\circledR}$ ', conventional and organic 'Honeycrisp', 'Zestar! ${ }^{\mathrm{TM}}$, and 'SnowSweet $\AA$ '. No conclusion about organic vs. conventional apples can be drawn from these data because the 
organic 'Honeycrisp' were grown in a different part of the United States than the conventional 'Honeycrisp' and were only compared against the conventional 'Honeycrisp' once. Differing preferences among participants may have been due to growing location rather than method.

The ranking of preferences for the rest of the apple varieties differed between frequent and infrequent buyers. For example, frequent buyers disliked 'Fuji' the most, while infrequent buyers disliked 'Sweet Sixteen' the most. One possible reason for disliking of 'Sweet Sixteen' is that temperatures during the growing season in 2009 were unusually cool (data not shown) when 'Sweet Sixteen' was included in the study, so its fruit did not develop its characteristic "cherry candy" flavor.

WTP FOR APPLE VARIETIES. The coefficients of price were negative ( $\mathrm{Ta}-$ ble 3 ), meaning that as price increased, the likelihood of participants choosing the corresponding apple variety decreased. The sum of the constant coefficient and the coefficient of an apple variety divided by the sum of the coefficient of price results in participants' WTP for a particular apple variety (Yue and Tong, 2009). For example, frequent buyers' WTP for 'Honeycrisp' apples is $(3.05-0.87) / 0.99$. The delta method was used to estimate the standard error of the calculated WTP (Greene, 2002). The mean and standard error of estimated WTP are shown in Table 4 . We conducted a $t$ test to determine whether the WTP for an apple variety was significantly different from zero. Additionally, we conducted $t$ test statistics to test if frequent buyers' WTP for an apple variety was significantly different from that of infrequent buyers, and the results are shown in the last column of Table 4.

From Table 4, we can see that frequent buyers were willing to pay $\$ 3.09 / \mathrm{lb}$ for 'SweeTango ${ }^{\circledR}$ ' apples and infrequent buyers were willing to pay the significantly higher amount of $\$ 3.2 \mathrm{l} / \mathrm{lb}$. Frequent and infrequent buyers were willing to pay $\$ 2.20 / \mathrm{lb}$ and $\$ 2.24 / \mathrm{lb}$, respectively for 'Honeycrisp' apples. Frequent and infrequent buyers were willing to pay $\$ 2.63 / \mathrm{lb}$ and $\$ 2.46 / \mathrm{lb}$, respectively for 'Zestar!' apples. For organic 'Honeycrisp' apples, the WTP was $\$ 2.63 / \mathrm{lb}$ and $\$ 2.51 / \mathrm{lb}$ for frequent and infrequent buyers, respectively. Participants' WTP for the rest of the apple varieties were lower
Table 3. Mixed logit models estimation results for apple variety choice data for frequent and infrequent buyers participating in apple tasting choice experiments at a farmers' market and a supermarket in the Minneapolis-St. Paul, MN area in 2009 and $2010(N=266)$.

\begin{tabular}{|c|c|c|c|c|}
\hline \multirow[b]{2}{*}{ Variable } & \multicolumn{2}{|c|}{ Model 1: Frequent buyer } & \multicolumn{2}{|c|}{ Model 2: Infrequent buyer } \\
\hline & Coefficient & SE & Coefficient & SE \\
\hline Constant & $3.05 * * * z$ & 0.65 & $2.15 * * *$ & 0.47 \\
\hline 'SweeTango $®$ 'y & Base & & Base & \\
\hline 'Honeycrisp' & $-0.87 * * *$ & 0.18 & $-0.65 * * *$ & 0.13 \\
\hline 'Zestar! 'TM' & $-0.45^{* *}$ & 0.20 & $-0.50 * * *$ & 0.15 \\
\hline 'Keepsake' & $-2.04 * * *$ & 0.43 & $-1.67 * * *$ & 0.31 \\
\hline 'Sweet Sixteen' & $-2.55^{* * *}$ & 0.36 & $-2.50 * * *$ & 0.28 \\
\hline 'Ginger Gold' & $-2.06 * * *$ & 0.38 & $-1.44 * * *$ & 0.28 \\
\hline Organic 'Honeycrisp' & -0.45 & 0.34 & $-0.47 * *$ & 0.23 \\
\hline 'Snow Sweet ${ }^{\circledR}$ ' & -0.96 ** & 0.37 & $-0.83^{* * *}$ & 0.27 \\
\hline 'Haralson' & $-2.20 * * *$ & 0.43 & $-1.73 * * *$ & 0.30 \\
\hline 'Connell Red' & $-1.78 * * *$ & 0.43 & $-1.48 * * *$ & 0.31 \\
\hline 'Cortland' & $-2.46^{* * *}$ & 0.42 & $-1.87 * * *$ & 0.29 \\
\hline 'Fuji' & $-2.57 * * *$ & 0.36 & $-1.62 * * *$ & 0.24 \\
\hline 'Gala' & $-1.93 * * *$ & 0.38 & $-1.87 * * *$ & 0.28 \\
\hline 'Jazz'T, & $-2.50 * * *$ & 0.42 & $-1.41 * * *$ & 0.29 \\
\hline Price & $-0.99 * * *$ & 0.21 & $-0.67 * * *$ & 0.15 \\
\hline \multicolumn{5}{|l|}{ Demographic variable ${ }^{\mathrm{x}}$} \\
\hline Age & -0.10 & 0.07 & -0.05 & 0.05 \\
\hline Gender & -0.03 & 0.06 & 0.00 & 0.04 \\
\hline Household & 0.06 & 0.05 & -0.04 & 0.05 \\
\hline Education & -0.01 & 0.05 & 0.04 & 0.05 \\
\hline Income & 0.05 & 0.07 & -0.06 & 0.05 \\
\hline
\end{tabular}

Individual effects

$\sigma_{\eta}$

0.08

0.29

0.16

0.10

'The coefficients of the apple varieties were estimated relative to the base variety 'SweeTango'.

'The apple variety variables were coded as dummy variables. For example, 'Honeycrisp' $=1$ if the apple was 'Honeycrisp' and 0 if the apple was another variety.

'The demographic variables were standardized, which makes interpretation of the apple varieties' coefficients' straightforward because the interaction effects had zero means and unitary standard deviations.

$* * *, * *{ }^{*}$ Significant at $1 \%, 5 \%$, or $10 \%$ significance level, respectively.

Table 4. Estimated willingness to pay (WTP) for various apple varieties by frequent and infrequent buyers participating in apple tasting choice experiments at a farmers' market and a supermarket in the Minneapolis-St. Paul, MN area in 2009 and $2010(N=266)$.

\begin{tabular}{|c|c|c|c|c|c|}
\hline \multirow[b]{2}{*}{ Variety } & \multicolumn{2}{|c|}{ Frequent buyer } & \multicolumn{2}{|c|}{ Infrequent buyer } & \multirow{2}{*}{$\begin{array}{l}t \text { test statistics of } \\
\text { WTP differences }\end{array}$} \\
\hline & Mean & SE & Mean & SE & \\
\hline SweeTango® & $3.09 * * * z$ & 0.12 & $3.21 * * *$ & 0.14 & $-7.45 * * * y$ \\
\hline Honeycrisp & $2.20 * * *$ & 0.19 & $2.24 * * *$ & 0.20 & -1.60 \\
\hline Zestar! ${ }^{\mathrm{TM}}$ & $2.63^{* * *}$ & 0.15 & $2.46^{* * *}$ & 0.17 & $8.29^{* * *}$ \\
\hline Keepsake & $1.02 * * *$ & 0.35 & $0.72 *$ & 0.41 & $6.39 * * *$ \\
\hline Sweet Sixteen & 0.51 & 0.39 & -0.52 & 0.63 & $16.41 * * *$ \\
\hline Ginger Gold & $1.00 * * *$ & 0.25 & $1.06 * * *$ & 0.27 & -1.65 \\
\hline Honeycrisp (organic) & $2.63 * * *$ & 0.35 & $2.51 * * *$ & 0.37 & $2.57 * *$ \\
\hline SnowSweet ${ }^{\circledR}$ & $2.11 * * *$ & 0.26 & $1.96 * * *$ & 0.26 & $4.38 * * *$ \\
\hline Haralson & $0.86 * *$ & 0.40 & 0.62 & 0.45 & $4.50 * * *$ \\
\hline Connell Red & $1.29 * * *$ & 0.33 & $0.99 * * *$ & 0.37 & $6.65 * * *$ \\
\hline Cortland & $0.60 *$ & 0.36 & 0.41 & 0.40 & $3.93 * * *$ \\
\hline Fuji & 0.49 & 0.44 & $0.78 * *$ & 0.40 & $-5.29 * * *$ \\
\hline Gala & $1.14 * * *$ & 0.34 & 0.42 & 0.49 & $13.92 * * *$ \\
\hline $\mathrm{Jazz}^{\mathrm{TM}}$ & 0.56 & 0.38 & 1.10 *** & 0.32 & $-11.68 * * *$ \\
\hline
\end{tabular}

${ }^{2} t$ tests were conducted to test if the estimated WTP was significantly different from zero.

${ }^{y} t$ tests were conducted to test if frequent buyers' WTP was significantly different from that of infrequent buyers $* * *, * *{ }^{*}$ Significantly different from zero at $1 \%, 5 \%$, or $10 \%$ significance level, respectively. 
than for the previously mentioned four varieties of apples. Frequent and infrequent buyers did not differ significantly in their WTP for conventional 'Honeycrisp' and 'Ginger Gold', but their WTP differed significantly for the other apple varieties. For those apple varieties that frequent and infrequent buyers did differ in WTP, frequent buyers were willing to pay significantly higher prices than infrequent buyers except for 'SweeTango ${ }^{\circledR}$ ', 'Fuji', and 'Jazz ${ }^{\mathrm{TM}}$ '.

QUALITY ATTRIBUTE EVALUATION. From the choice experiment results, we found that the variety both frequent and infrequent buyers preferred most was 'SweeTango ${ }^{\circledR}$ '. They also liked 'Zestar! ${ }^{\mathrm{TM}}$ ' and 'Honeycrisp' apples. They were willing to pay a relatively higher price for these three apple varieties. To find out why participants liked them and in what quality aspects the three apple varieties were perceived as superior to the rest of the varieties, we asked participants if they liked a series of quality attributes of the apple varieties after they tasted the apples. The quality attributes participants evaluated were aroma, color, crispness, firmness, juiciness, sweetness, and tartness. If they liked the particular quality attribute, participants chose "yes," otherwise, "no." We used the Bonferroni $t$ test to determine if evaluation of these quality attributes for 'SweeTango ${ }^{\circledR}$ ', 'Honeycrisp', or 'Zestar! ${ }^{\mathrm{TM}}$, differed significantly from those of other apple varieties. The results are shown in Tables 5-7.

It is interesting how 'SweeTango ${ }^{\circledR}$ ' apples were perceived as improved compared with its parents, 'Honeycrisp', and 'Zestar! ${ }^{\mathrm{TM}}$. From Table 5, we can see that compared with 'Honeycrisp', participants considered the tartness and sweetness of 'SweeTango ${ }^{\circledR}$ ' apples as superior. Compared with 'Zestar! 'TM, the crispness and firmness of 'SweeTango ${ }^{\circledR}$ ' were liked better by participants. The sweetness of 'SweeTango ${ }^{\circledR}$ ' was considered better than that of organic 'Honeycrisp'. Compared with all other apple varieties except for 'SnowSweet ${ }^{\circledR}$ ', 'SweeTango ${ }^{\circledR}$ ' was considered as superior in at least four of the seven quality attributes. 'SweeTango ${ }^{\circledR}$ ' was considered superior to 'Connell Red' in terms of all the quality attributes, but its quality attributes were not considered as significantly different from those of 'SnowSweet ${ }^{\circledR}$ '. Almost all the quality attributes of 'SweeTango ${ }^{\circledR}$ ' were liked better than those of the rest of the varieties except for the crispness of 'Keepsake', the crispness, color, and firmness of 'Haralson', the color of 'Cortland', and the aroma of 'Fuji' and 'Gala'. The tartness,

Table 5. Bonferroni $t$ test results of participants' evaluations of apple quality attributes testing 'SweeTango®' against other apple varieties. Results were obtained at apple tasting choice experiments at a farmers' market and a supermarket in the Minneapolis-St. Paul, MN area in 2009 and $2010(N=266)$.

\begin{tabular}{|c|c|c|c|c|c|c|c|}
\hline \multirow[b]{2}{*}{ Variety } & Crispness & Tartness & Color & Aroma & Juiciness & Sweetness & Firmness \\
\hline & \multicolumn{7}{|c|}{ Bonferroni $t$ test } \\
\hline Honeycrisp & 0.44 & $2.34^{*}$ & -0.35 & 0.03 & 1.53 & $3.50 * * *$ & 1.53 \\
\hline Zestar! $^{\mathrm{TM}}$ & $3.56 * * *$ & -0.20 & 1.10 & -1.06 & 1.29 & 0.62 & $3.28 * * *$ \\
\hline Honeycrisp (organic) & -1.03 & 1.12 & 0.74 & -0.70 & 1.03 & $3.22 * * *$ & 0.15 \\
\hline Connell Red & $8.76^{* * *}$ & $6.05 * * *$ & $4.55 * * *$ & $3.55 * * *$ & $5.72 * * *$ & $5.21 * * *$ & $7.04 * * *$ \\
\hline SnowSweet ${ }^{\circledR}$ & 0.44 & 0.85 & 0.85 & 1.10 & 2.11 & -0.70 & 0.54 \\
\hline Cortland & $5.75 * * *$ & $3.38 * * *$ & 1.88 & $2.23^{*}$ & $4.78 * * *$ & $5.91 * * *$ & $5.62 * * *$ \\
\hline Fuji & $7.33 * * *$ & $6.73 * * *$ & $3.02 * *$ & 1.66 & $5.72 * * *$ & $8.12 * * *$ & $6.79 * * *$ \\
\hline Gala & $10.59 * * *$ & $6.82 * * *$ & $3.68 * * *$ & 1.19 & $8.24 * * *$ & $6.44 * * *$ & $10.96 * * *$ \\
\hline $\mathrm{Jazz}^{\mathrm{TM}}$ & 2.01 & $4.52 * * *$ & 1.99 & 0.03 & $3.16 * * *$ & $3.02 * *$ & $2.39 *$ \\
\hline
\end{tabular}

'Positive sign means evaluation of 'SweeTango ${ }^{\circledR}$ ' was higher than that of the corresponding variety.

$* * *, * *,{ }^{*}$ Significantly different at $1 \%, 5 \%$, or $10 \%$ significance level, respectively.

Table 6. Bonferroni $t$ test results of participants' evaluation of apple quality attributes testing 'Honeycrisp' against other apple varieties. Results were obtained at apple tasting choice experiments at a farmers' market and a supermarket in the Minneapolis-St. Paul, MN area in 2009 and $2010(N=266)$.

\begin{tabular}{|c|c|c|c|c|c|c|c|}
\hline \multirow[b]{2}{*}{ Variety } & Crispness & Tartness & Color & Aroma & Juiciness & Sweetness & Firmness \\
\hline & \multicolumn{7}{|c|}{ Bonferroni $t$ test } \\
\hline SweeTango ${ }^{\circledR}$ & -0.44 & $-2.34^{*}$ & 0.35 & -0.03 & -1.53 & $-3.50 * * *$ & -1.53 \\
\hline SnowSweet ${ }^{\circledR}$ & 0.08 & -1.03 & 1.13 & 1.07 & 0.78 & $-3.37 * * *$ & -0.67 \\
\hline Honeycrisp (organic) & -1.36 & -0.80 & 1.03 & -0.72 & -0.25 & 0.24 & -1.06 \\
\hline Keepsake & 0.72 & $2.66 * *$ & $3.32 * * *$ & $2.61 * *$ & $3.42 * * *$ & 2.34 * & 1.81 \\
\hline Fuji & $6.79 * * *$ & $4.54 * * *$ & $3.30 * * *$ & 1.63 & $4.20 * * *$ & $4.58 * * *$ & $5.19 * * *$ \\
\hline Gala & $9.94 * * *$ & $4.62 * * *$ & $3.96 * * *$ & 1.16 & $6.55 * * *$ & $3.15 * * *$ & $8.96 * * *$ \\
\hline $\mathrm{Jazz}^{\mathrm{TM}}$ & 1.61 & $2.49 * *$ & $2.27 *$ & -0.00 & 1.77 & 0.09 & 1.06 \\
\hline Zestar! $^{\mathrm{TM}}$ & $3.13 * * *$ & -2.07 & 1.39 & -1.09 & -0.00 & -2.16 & 1.89 \\
\hline
\end{tabular}

${ }^{2}$ Positive sign indicates that evaluation of 'Honeycrisp' was higher than that of the corresponding variety.

$* * *, * *,{ }^{*}$ Significantly different at $1 \%, 5 \%$, or $10 \%$ significance level, respectively. 
Table 7. Bonferroni $t$ test results of participants' evaluation of apple quality attributes testing 'Zestar! ' ${ }^{\mathrm{TM}}$ ' versus other apple varieties. Results were obtained at apple tasting choice experiments at a farmers' market and a supermarket in the Minneapolis-St. Paul, MN area in 2009 and $2010(N=266)$.

\begin{tabular}{|c|c|c|c|c|c|c|c|}
\hline \multirow[b]{2}{*}{ Variety } & Crispness & Tartness & Color & Aroma & Juiciness & Sweetness & Firmness \\
\hline & \multicolumn{7}{|c|}{ Bonferroni $t$ test } \\
\hline SweeTango® & $-3.56^{* * *}$ & 0.20 & -1.10 & 1.06 & -1.29 & -0.62 & $-3.28 * * *$ \\
\hline SnowSweet ${ }^{\circledR}$ & $-2.48^{*}$ & 0.90 & -0.19 & 1.87 & 0.67 & -1.14 & -2.16 \\
\hline Honeycrisp & $-3.13^{* * *}$ & 2.07 & -1.39 & 1.09 & 0.00 & 2.16 & -1.89 \\
\hline Honeycrisp (organic) & $-3.80 * * *$ & 1.13 & -0.29 & 0.3 & -0.21 & 2.13 & $-2.53 * *$ \\
\hline Cortland & 1.69 & $3.06 * * *$ & 0.66 & $2.73^{* *}$ & $2.74 * *$ & $4.33^{* * *}$ & 1.84 \\
\hline Fuji & $2.82 * *$ & $6.02 * * *$ & 1.57 & $2.36^{*}$ & $3.43 * * *$ & $6.14^{* * *}$ & $2.65^{* *}$ \\
\hline Gala & $5.08 * * *$ & $6.09 * * *$ & 2.07 & 1.97 & $5.30 * * *$ & $4.76 * * *$ & $5.62 * * *$ \\
\hline $\mathrm{Jazz}^{\mathrm{TM}}$ & -1.21 & $4.03 * * *$ & 0.74 & 0.96 & 1.48 & 1.98 & -0.68 \\
\hline
\end{tabular}

${ }^{2}$ Positive sign indicates that evaluation of ' $Z e^{2}$ tar $^{\mathrm{TM}}$, was higher than that of the corresponding variety.

$* * *, * *,{ }^{*}$ Significantly different from zero at $1 \%, 5 \%$, or $10 \%$ significance level, respectively.

juiciness, sweetness, and firmness of 'SweeTango ${ }^{\circledR}$ ' were considered as better than those of 'Jazz ${ }^{\mathrm{TM}}$ '.

We further investigated how the quality attributes of 'Honeycrisp' was considered as different from that of the other apple varieties. From Table 6, we can see that the crispness of 'Honeycrisp' was considered superior to that of 'Connell Red', 'Cortland', 'Fuji', 'Gala', and 'Zestar!' was thought of as better than that of 'Connell Red', 'Keepsake', 'Fuji', 'Gala', and 'Jazz ${ }^{\mathrm{TM}}$ '. Its color was perceived as better than that of 'Connell Red', 'Keepsake', 'Fuji', 'Gala', and 'Jazz ${ }^{\mathrm{TM}}$ ', Its aroma was better liked than that of 'Connell Red', 'Keepsake', and 'Haralson'. Its juiciness was preferred to that of most other varieties except for 'SweeTango ${ }^{\circledR}$ ', 'SnowSweet ${ }^{\circledR}$ ', organic 'Honeycrisp', 'Jazz ${ }^{\mathrm{TM}}$, and 'Zestar! 'MM,. Its sweetness was considered as better than that of 'Keepsake', 'Haralson', 'Cortland', 'Fuji', and 'Gala'. Its firmness was thought of as better than that of 'Connell Red', 'Cortland', 'Fuji', and 'Gala'. On the other hand, its sweetness was considered worse than that of 'SweeTango ${ }^{\circledR}$ ' and 'SnowSweet ${ }^{\circledR}$ '.

The same comparison estimation was conducted for 'Zestar! ${ }^{\mathrm{TM}}$, Table 7). The crispness of 'Zestar! ${ }^{\mathrm{TM}}$, was perceived as better than that of 'Connell Red', 'Fuji', and 'Gala' but considered as worse than that of 'SweeTango ${ }^{\circledR}$ ', 'SnowSweet ${ }^{\circledR}$ ', and conventional and organic 'Honeycrisp'. Its tartness was considered as better than that of almost all the rest of the varieties except for 'SweeTango ${ }^{\circledR}$ ', 'SnowSweet ${ }^{\circledR}$ ', and conventional and organic 'Honeycrisp'.
Its color was thought of as better than that of 'Connell Red'. Its aroma was considered as better than that of 'Connell Red', 'Keepsake', 'Haralson', 'Cortland', and 'Fuji'. Its juiciness and sweetness were considered as better than that of 'Connell Red', 'Keepsake', 'Haralson', 'Cortland', 'Fuji', and 'Gala'. Its firmness was perceived as superior to that of 'Connell Red', 'Fuji', and 'Gala' but worse than that of 'SweeTango ${ }^{\circledR}$ ' and organic 'Honeycrisp'.

\section{Conclusions and discussion}

To evaluate consumer preferences, WTP, and quality attribute preferences of existing and new apple varieties, we integrated several experimental methods: a choice experiment, apple tasting quality evaluation, and a follow-up survey. To avoid decontextualized bias, we conducted our experiments in real markets-a farmers' market and a supermarket-where consumers make fruit and vegetable purchases. We found differences in preferences, WTP, and quality evaluation between frequent and infrequent apple buyers. Generally speaking, consumers revealed stronger preferences and were willing to pay more for newer rather than more established apple varieties. For example, the newest apple variety, 'SweeTango ${ }^{\circledR}$ ', appealed to consumers the most. Compared with its parents, 'Zestar! ${ }^{\mathrm{TM}}$, and 'Honeycrisp', 'SweeTango ${ }^{\circledR}$ ' was considered superior in terms of firmness and crispness, and tartness and sweetness, respectively.

In analyzing the mean WTP for existing and new apple varieties, we found possible higher premiums for new apple varieties due to more desired quality attributes. The implications for the apple industry are that there are opportunities to market these new apple varieties by charging relatively higher prices. One of the pricing strategies for a new product is skimming pricing, which means that the new product is charged a high and premium price. If a product is highly desirable and liked by consumers, demand tends to be price inelastic during the introductory stage, allowing sellers to recover research, development, and promotional costs (Solomon and Stuart, 2003). Since consumers liked these three new apple varieties, a skimming pricing strategy would be very likely to succeed in the marketplace.

Our study also provides important marketing implications to existing apple varieties in terms of pricing strategies. Even under the best economic situation, consumers consider "reasonable price" as one of the most important factors when they make purchasing decisions (Solomon and Stuart, 2003). Our study provides important information on consumer WTP for 11 existing apple varieties for both frequent and infrequent apple buyers. By charging for these apple varieties at or below these levels while still above costs, marketers are likely to attract more potential consumers, which can potentially generate larger market share and glean higher profits.

In addition to WTP estimates, our study also shows what quality attributes consumers consider as improvements compared with existing varieties. Combined with objective measures of these quality attributes, our transdisciplinary study will help 
apple breeders make more targeted breeding decisions by better understanding what quality attributes consumers like or dislike about the studied apple varieties. Improved targeting of breeding decisions will ensure more successful new variety development, which will help maintain a comparative advantage of the apple industry.

In closing, our experiments were conducted in the Minneapolis-St. Paul metropolitan area so we are pretty confident that our sample was representative of Minnesota or midwestern U.S. consumers. We would extrapolate our results to other regions of the country with caution. Further studies in other regions are needed to validate the results of the study.

\section{Literature cited}

Alfnes, F., A. Guttormsen, G. Steine, and K. Kolstad. 2006. Consumers' willingness to pay for the color of salmon: A choice experiment with real economic incentives. Amer. J. Agr. Econ. 88:1050-1061.

Axelson, E.L. and J. Axelson. 2000. Hypercompetition on horticultural markets. Acta Hort. 536:485-492.
Greene, W.H. 2002. Econometric Analysis, 5th ed. Prentice Hall, New Jersey.

Harker, F.R., F.A. Gunson, and S.R. Jaeger. 2003. The case for fruit quality: An interpretive review of consumer attitudes, and preferences for apples. Postharvest Biol. Technol. 28:333-347.

Loureiro, L.M. and S. Hine. 2002. Discovering niche markets: A comparison of consumer willingness to pay for local (Colorado Grown), organic, and GMO-free products. J. Agr. Appl. Econ. 34:477-487.

Loureiro, L.M., J.J. McCluskey, and R.C. Mittelhammer. 2002. Will consumers pay a premium for eco-labeled apples? J. Consum. Aff. 36:203-219.

Louviere, J.J., D.A. Hensher, and J.D. Swait. 2000. Stated choice methods: Analysis and application. Cambridge University Press, Cambridge, UK.

Lusk, J.L. and T.C. Schroeder. 2004. Are choice experiments incentive compatible? A test with quality differentiated beef steaks. Amer. J. Agr. Econ. 86:467-482.

McCluskey, J.J., R.C. Mittelhammer, A.B. Marin, and K.S. Wright. 2007. Effect of quality characteristics on consumers' willingness to pay for Gala apples. Can. J. Agr. Econ. 55:217-231.
Rozan, A., A. Stenger, and M. Willinger. 2004. Willingness-to-pay for food safety: An experimental investigation of quality certification on bidding behavior. Eur. Rev. Agr. Econ. 31:409-425.

Solomon, M.R. and E. Stuart. 2003. Marketing: Real people, real choices. 5 th ed. Prentice Hall, Upper Saddle River, NJ.

The Packer. 2010. Category spotlight: Apples, p. 16-18. In: Fresh trends 2010. Vance Publishing, Lenexa, KS.

Yue, C., F. Alfnes, and H.H. Jensen. 2009. Discounting spotted apples: Investigating consumers' willingness to accept cosmetic damage in an organic product. J. Agr. Appl. Econ. 14:29-46.

Yue, C., H.H. Jensen, D. Mueller, G. Nonnecke, and M. Gleason. 2007. Estimating consumers' valuation of organic and cosmetically damaged apples. HortScience 42:1366-1371.

Yue, C. and C. Tong. 2009. Organic or local? Investigating consumer preference for fresh produce using a choice experiment with real economic incentives. HortScience 44:366-371. 